\title{
Ferramenta com recurso de voz: uma proposta para favorecer o processo de interação e inclusão dos cegos em ambientes virtuais de aprendizagem
}

Regina Barwaldt

Orientador(a): Profa. Dra. Lucila Maria Costi Santarosa

Coorientador: Profa. Dra. Liliana Maria Passerino

Data de defesa: 03 de dezembro de 2008

Esta pesquisa aborda o uso e a apropriação das Tecnologias de Informação e de Comunicação (TIC's) pelas pessoas com cegueira através de uma ferramenta de interação social síncrona com áudio acessível em um AVA, implementada conforme padrões de acessibilidade da W3C/ WAI. Fazem parte deste processo, sujeitos cegos e videntes, professores do curso Projeto de Informática na Educação Especial (PROINESP), da Secretaria de Educação Especial do Ministério da Educação (SEESP/MEC) em parceria com a Universidade Federal do Rio Grande do Sul (UFRGS), através do Núcleo de Informática na Educação Especial (NIEE) e do Centro Interdisciplinar de Novas Tecnologias na Educação (CINTED). O problema de pesquisa verificou como uma ferramenta de conversação com recursos de áudio, coerente aos princípios de acessibilidade, inserida em um contexto AVA, favorece a interação das pessoas cegas com vistas à sua inclusão digital, social e educacional em cursos na modalidade a distância. Dentre os objetivos destacou-se desenvolver e validar a ferramenta com recursos de áudio acessível, assim como, a estruturação da ferramenta integrada em um AVA's e, por conseguinte, a análise do processo de interação entre os cegos e videntes através da ferramenta EVOC. Para a análise foram estabelecidas categorias focadas principalmente na interação social, através de um arcabouço com base na teoria sócio-histórica, que foi a linha mestra deste processo. A partir das análises realizadas dos processos interativos dos sujeitos desta pesquisa, concluiu-se que os mesmos utilizaram a ferramenta EVOC na realização do curso e interagiram entre eles e com videntes. Dessa forma, o estudo apresenta indício que a ferramenta favorece o processo de interação e inclusão de cegos em um contexto AVA, através da qualificação em cursos na modalidade à distância.

Palavras-chave: acessibilidade em EAD; Ambientes Virtuais de Aprendizagem; Cegos; Educação Especial; Inclusão digital; I nteração social. 